\title{
The Glucocorticoid Receptor as a Potential Target to Reduce Cocaine Abuse
}

\author{
Véronique Deroche-Gamonet, ${ }^{1 \star}$ Inge Sillaber, ${ }^{2 \star}$ Bruno Aouizerate, ${ }^{1}$ Ryozuke Izawa, ${ }^{1}$ Mohamed Jaber, ${ }^{1}$ \\ Sandy Ghozland, ${ }^{1}$ Christoph Kellendonk, ${ }^{3}$ Michel Le Moal, ${ }^{1}$ Rainer Spanagel, ${ }^{4}$ Günther Schütz, ${ }^{3}$ François Tronche, ${ }^{3,5}$ \\ and Pier Vincenzo Piazza ${ }^{1}$ \\ ${ }^{1}$ Institut National de la Santé et de la Recherche Médicale, Unité 588, Bordeaux 33077, France, ${ }^{2}$ Max Planck Institute of Psychiatry, D-80804 Munich, \\ Germany, ${ }^{3}$ Molecular Biology of the Cell I, Deutsches Krebsforschungzentrum, 69120 Heidelberg, Germany, ${ }^{4}$ Department of Psychopharmacology, Central \\ Institute of Mental Health, University of Heidelberg, 68159 Mannheim, Germany, and ${ }^{5}$ Centre National de la Recherche Scientifique, FRE2401, Institut de \\ Biologie, Collège de France, Paris 75231 Cedex 5, France
}

\begin{abstract}
Several findings suggest that glucocorticoid hormones are involved in determining the propensity of an individual to develop cocaine abuse. These hormones activate two related transcription factors, the glucocorticoid receptor (GR) and the mineralocorticoid receptor. In this study, we show that the selective inactivation of the GR gene in the brains of mice profoundly flattened the dose-response function for cocaine intravenous self-administration and suppressed sensitization, two experimental procedures considered relevant models of addiction. Furthermore, administration of a GR antagonist dose-dependently reduced the motivation to self-administer cocaine. Importantly, the absence of GR did not modify the basal behavioral and molecular effects of cocaine but selectively modified the excessive response to the drug spontaneously present in certain vulnerable individuals or induced by repeated drug exposure in others. In conclusion, we provide the first genetic evidence that the GR gene can modulate cocaine abuse. This suggests that targeting GR function in the brain could provide new therapeutic strategies to treat cocaine addiction for which there is no available treatment.
\end{abstract}

Key words: cocaine; self-administration; intravenous; sensitization; glucocorticoid receptor; mifepristone; transgenic; c-Fos

\section{Introduction}

Glucocorticoid hormones (GCs) have been involved in the determination of the propensity of an individual to develop cocaine abuse (Piazza and Le Moal, 1997; Goeders, 2002). Thus, GCs facilitate acquisition, maintenance, and relapse of cocaine selfadministration (SA) (Piazza et al., 1991; Goeders and Guerin, 1996; Deroche et al., 1997; Mantsch and Goeders, 1999). Furthermore, a functional hyperactivity of GCs has been found in individuals in whom a higher vulnerability to drugs is spontaneously present (Piazza and Le Moal, 1997) or has been induced by chronic stress (Piazza and Le Moal, 1998). Clearly, these results could have important implications for developing new strategies to treat cocaine abuse for which there is no available treatment. However, an essential step for pursuing this goal is the identification of the brain receptor mediating the effects of GCs on behavioral responses to cocaine.

GCs act on the mammalian brain through two main receptors (McEwen et al., 1986; De Kloet et al., 1998; Sapolsky et al., 2000), the mineralocorticoid receptor and the glucocorticoid receptor (GR). These receptors are transcription factors belonging to the superfamily of nuclear receptors (Beato et al., 1995). They mod-

Received Dec. 9, 2002; revised March 21, 2003; accepted March 21, 2003.

This work was supported by Deutscher Akademischer Austauschdienst Grant 312/pro-ms, by a grant from the French Ministry of Research (Action Concertée Incitative 2001, Integrative Physiology), and by grants from Institut National de la Santé et de la Recherche Médicale and University of Bordeaux II.

*V.D.-G. and I.S. contributed equally to this work.

Correspondence should be addressed to Dr. Pier Vincenzo Piazza, Institut National de la Santé et de la Recherche Médicale, Unité 588, Domaine de Carreire, Rue Camille Saint-Saëns, 33077 Bordeaux, France. E-mail: piervincenzo.piazza@bordeaux.inserm.fr.

Copyright $\odot 2003$ Society for Neuroscience $\quad$ 0270-6474/03/234785-06\$15.00/0 ulate target gene transcription after binding to DNA or by interfering with the activity of other transcription factors. In addition, several nongenomic effects of GCs have been described previously (Makara and Haller, 2001). Although the molecular mechanisms mediating these effects remain unknown, some rapid effects of GCs seem to involve the GR (Hafezi-Moghadam et al., 2002). Unfortunately, available data do not allow precise definition of which of these substrates mediate the effects of GCs on behavioral responses to cocaine.

We investigated the molecular basis of the interaction between GCs and the behavioral effects of cocaine by using mice that had the GR gene specifically inactivated in the CNS. These mutants, generated using the Cre-loxP system (Tronche et al., 1999), allow differentiation between the potential involvement of peripheral versus central receptors and provide the only available approach to analyze the behavioral role of GRs, because the invalidation of the gene is lethal. We studied the following two behavioral responses to cocaine: (1) cocaine-induced intravenous SA, which is considered the best experimental model of drug abuse (Schuster and Thompson, 1969; Koob and Weiss, 1990), and (2) cocaine-induced behavioral sensitization, which is defined by the increase in the behavioral effects of cocaine that is observed over repeated drug injections and is a process that is proposed to be involved in the development of addiction (Robinson and Berridge, 1993). We also studied the expression of the mRNA of the immediate early gene c-fos, which is considered to be a measure of neuronal activation by cocaine and may be involved in the cellular changes leading to addiction (Nestler, 2001).

We found that GRs mediate cocaine-induced SA and sensiti- 
zation in mice. These results prompted us to test the effects of the most frequently used GR antagonist mifepristone (Gagne et al., 1985 ) on cocaine SA in rats. Mifepristone profoundly reduced the motivation to self-administer cocaine. Clearly, these results could have important implications for developing new strategies to treat cocaine abuse.

\section{Materials and Methods \\ Animals}

Mice. Using the Cre-loxP recombination system, mice with GR inactivation in the nervous system were generated (Tronche et al., 1999). Male Grl1 ${ }^{\text {loxP/loxP }}$ NesCre $\left(\mathrm{GR}^{\text {NesCre }}\right)$ mice and their corresponding controls (Grl1 ${ }^{\text {loxP/loxP }}$ ) were used (Tronche et al., 1999). Animals were 3-4 months of age when tested.

Rats. Three-month-old male Sprague Dawley rats (Iffa Credo, Lyon, France) (300-350 gm) were used. Animals were individually housed and had ad libitum access to food and water. A $12 \mathrm{hr}$ light/dark cycle was used in the animal houses of both rats and mice. Temperature $\left(22 \pm 1^{\circ} \mathrm{C}\right)$ and humidity $(60 \pm 5 \%)$ were controlled. The sensitization experiment was performed during the light period, and the SA experiments were performed during the dark period.

\section{Intravenous $S A$}

Although different sizes, the SA chambers (Imetronic, Pessac, France) for mice $(18 \mathrm{~cm}$ long $\times 11 \mathrm{~cm}$ wide $\times 15 \mathrm{~cm}$ high $)$ and rats $(40 \mathrm{~cm}$ long $\times 30$ $\mathrm{cm}$ wide $\times 52 \mathrm{~cm}$ high) were built on the same principle. Each chamber contained two holes located on each of the two smaller walls; the holes were equipped with photobeams to detect nose-poke responses. As described previously (Deroche et al., 1997), $6 \mathrm{~d}$ after catheter implantation, each animal was placed daily in an SA chamber, in which its chronically implanted intracardiac catheter was connected to a pump-driven syringe through a single-channel swivel and Tygon tubing. The introduction of the animal's nose into one hole (active device) switched on the infusion pump (infusion speed, $20 \mu \mathrm{l}$ over $1 \mathrm{sec}$ ). For mice, it also turned on a cue light for a total of $4 \mathrm{sec}$, starting $1 \mathrm{sec}$ before the infusion. Nose pokes in the other hole (inactive device) resulted in no scheduled consequences. Each infusion was followed by a $20 \mathrm{sec}$ time-out period for rats and a 40 sec time-out period for mice. Experimental contingencies were controlled, and data were collected by PC Windows-compatible software (SK-AA; Imetronic). The criterion for stabilization was considered a variation in responding of $<10 \%$ over 2 consecutive days.

\section{Motor activity}

Motor activity was measured in Plexiglas cages $(19 \mathrm{~cm}$ long $\times 11 \mathrm{~cm}$ wide $\times 14 \mathrm{~cm}$ high) placed in frames mounted with computermonitored photocell beams (Imetronic). The horizontal locomotion frames consisted of two couples of parallel beams. In each couple, the two beams were separated by $3 \mathrm{~cm}$. The distance between the two couples was $12 \mathrm{~cm}$. Horizontal locomotion was estimated by the number of cage crossings (i.e., consecutive breaks of the two couples of beams).

\section{In situ hybridization}

In situ hybridization was performed on frontal sections $(12 \mu \mathrm{m})$ with a c-fos oligonucleotide probe (5'-GTTGACAGGAGAGCCCATGCTGGAGAAGGAGTCGGCTGGGGAATG-3'), labeled by tailing with $\left[{ }^{35} \mathrm{~S}\right]$ deoxyadenosine triphosphate (NEN, Boston, MA), with a specific activity of $2 \times 10^{9} \mathrm{cpm} / \mathrm{mg}$, as described previously (Jaber et al., 1999). Sections were exposed at room temperature to $\mathrm{x}$-ray films (Biomax MR; Eastman Kodak, Rochester, NY) for $30 \mathrm{~d}$. The quantification procedure was performed with a Biocom (Les Ulis, France) 200 image analyzer. Probe concentration and exposure times were chosen to stay within a linear range of detection. Samples from individual animals were analyzed in triplicate. Six structures were analyzed according to the mouse brain stereotaxic atlas by Franklin and Paxinos (1997): nucleus accumbens core, nucleus accumbens shell, dorsolateral striatum, mediodorsal striatum, motor cortex, and prefrontal cortex.

\section{Protocols}

Cocaine SA in GR ${ }^{\text {NesCre }}$ mice. Seven Grl1 ${ }^{\text {loxP/loxP }}$ (controls) and seven $\mathrm{GR}^{\mathrm{Nes} C r e}$ mice were trained to self-administer cocaine during one daily 1 hr session. Animals were first tested for acquisition at the dose of 2 $\mathrm{mg} \cdot \mathrm{kg}^{-1} \cdot$ infusion $^{-1}$. During this period, the ratio was progressively increased from 1 to 5 [ $4 \mathrm{~d}$ at fixed ratio 1 (FR1), $1 \mathrm{~d}$ at FR2, $1 \mathrm{~d}$ at FR3, and $5 \mathrm{~d}$ at FR5]. After stabilization of the behavior, a dose-response study was performed. Six doses were successively tested in a descending order (1, $0.5,0.25,0.125,0.06$, and $0.03 \mathrm{mg} \cdot \mathrm{kg}^{-1} \cdot$ infusion $^{-1}$ ) (see Fig. $\left.1 a\right)$. Each dose was tested during at least 4 consecutive days and until the criteria for stabilization were met.

Cocaine-induced behavioral and neuronal sensitization in $G R^{\text {NesCre }}$ mice. Controls and GR ${ }^{\text {NesCre }}$ mice received a pretreatment of nine injections of either cocaine ( $15 \mathrm{mg} / \mathrm{kg}$, i.p.; $n=10$ for controls; $n=13$ for $\left.\mathrm{GR}^{\mathrm{Nes} C r e}\right)$ or vehicle $(0.9 \% \mathrm{NaCl}$ solution; $10 \mathrm{ml} / \mathrm{kg}$, i.p.; $n=20$ for controls; $n=20$ for $\mathrm{GR}^{\text {NesCre }}$ ) once per day, every second day. Tests for sensitization were performed on the third day and on the 30th day after the last injection of the pretreatment. On the first and the second tests, cocaine-pretreated animals (chronic cocaine group) as well as one-half of the saline-pretreated mice (acute cocaine group) received a cocaine injection $(7.5 \mathrm{mg} / \mathrm{kg}$, i.p), and the other saline-pretreated animals were administered vehicle (vehicle group). For both tests, mice were placed in the activity cages $2 \mathrm{hr}$ after the beginning of the light period immediately after the injection. Horizontal activity was monitored during $40 \mathrm{~min}$. Animals were killed $5 \mathrm{~min}$ after the end of the second test for sensitization. Brains were removed, shock-frozen using isopentane on dry ice, and stored at $-80^{\circ} \mathrm{C}$ until use for in situ hybridization.

Effect of mifepristone on cocaine $S A$ in rats. Twelve rats were trained to self-administer cocaine $\left(1 \mathrm{mg} \cdot \mathrm{kg}^{-1} \cdot\right.$ infusion $\left.^{-1}\right)$ during one daily $1 \mathrm{hr}$ session. After acquisition and stabilization of SA behavior (15 sessions; $4 \mathrm{~d}$ at FR1; $1 \mathrm{~d}$ at FR3; and $10 \mathrm{~d}$ at FR5), a within-session progressive ratio schedule was applied [i.e., within the same session, the ratio requirement (number of responses required to receive one infusion) was progressively increased from 1 to 1613]. In this case, SA sessions lasted $5 \mathrm{hr}$. Once behavior was stabilized (stable breaking point over two consecutive sessions; $\pm 10 \%$ variation), the effects of mifepristone were tested using a Latin square design. The breaking point was considered to be the last ratio completed by the animal followed by $1 \mathrm{hr}$ during which no additional infusion was earned. This criterion was also used to terminate the session.

\section{Data analyses}

Data were analyzed by using ANOVA for repeated measures, followed when required by appropriate post hoc comparisons.

\section{Results \\ Cocaine SA in $\mathrm{GR}^{\mathrm{Nes} C r e}$ mice}

Animals in which the CNS GR gene was inactivated (GR ${ }^{\text {NesCre }}$ ) did not differ from control littermates in acquisition of cocaine SA when high doses of the drug $(2 \mathrm{mg} / \mathrm{kg})$ and a low ratio requirement were used (Fig. 1a). Thus, over the 11 sessions of the acquisition period, the two genotypes showed an equal rate of responding on the device giving access to cocaine and similar discrimination between the active and inactive devices (hole effect, $F_{(1,11)}=9.34, p<0.01$; hole $\times$ genotype interaction, $F_{(1,11)}=0.05, p=0.82$; hole $\times$ session $\times$ genotype interaction, $\left.F_{(10,110)}=1.07, p=0.38\right)$. These results indicate that the two genotypes are equally capable of learning intravenous SA.

In contrast, the dose-response function for cocaine SA (Fig. 1b) profoundly differed in $\mathrm{GR}^{\mathrm{Nes} C r e}$ animals and control littermates. In control mice, a classical bell-shaped dose-response function was observed, characterized by an increase in responding as the dose of cocaine per infusion decreased. This behavior is usually interpreted as an attempt by the animal to maintain an ideal level of reinforcement up to the point when the unitary dose is too low to efficiently reinforce SA (Piazza et al., 2000). In contrast, in mutant animals, the dose-response function for cocaine SA was profoundly flattened and shifted downward (genotype effect, $F_{(1,11)}=6.73, p<0.05$; genotype $\times$ dose interaction, $\left.F_{(6,66)}=3.33, p<0.01\right)$. Vertical downward shifts in dose- 


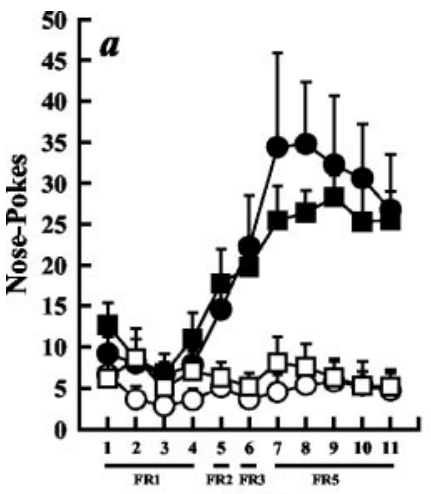

Days

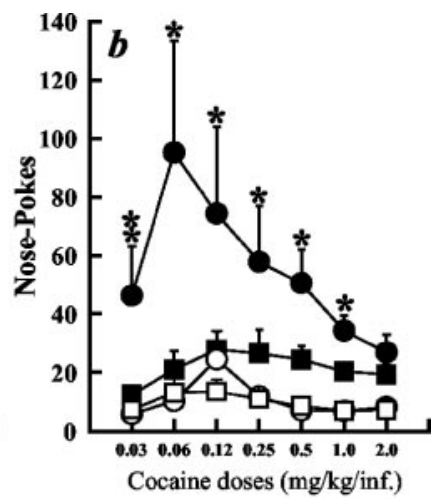

Cocaine doses $(\mathrm{mg} / \mathrm{kg} / \mathrm{inf}$.)

Figure 1. CNS knock-out of the GR (GR ${ }^{\text {NesCre }}$ ) and control littermates differed in cocaine $S A$ dose-response function but not in acquisition of this behavior. $a, 0 \mathrm{ver}$ the $11 \mathrm{~d}$ of the acquisition period, the two genotypes showed an equal rate of responding on the device giving access to cocaine (active hole; GR ${ }^{\text {NesCre }}, \mathbf{\square}$; controls, $O$ ) and a similar discrimination between the active and inactive devices. Responding on the inactive hole (GR ${ }^{\text {NesCre }}, \square$; controls, $\bigcirc$ ) did not result in scheduled consequences and was used as a control of SA. FR1-FR5 indicate the number of responses required to obtain one infusion. The bars below the $x$-axis indicate the number of days each $F R$ was applied. Data are expressed as the mean daily number of nose pokes ( \pm SEM). $b$, The dose-response function profoundly differed between the two genotypes and was flattened and shifted downward in GR ${ }^{\text {NesCre }}$ animals ( $\square$ ) compared with that in control littermates (O). Data are expressed as the mean number ( \pm SEM) of active (GR ${ }^{\text {NesCre }}, \mathbf{\square}$; controls, $O$ ) and inactive (GR ${ }^{\text {NesCre }}, \square$; controls, $\bigcirc$ ) nose pokes over the last two sessions for each dose. ${ }^{*} p<$ 0.05 compared with

response function, like the one observed in mutant mice, predict a lower motivation to self-administer cocaine and a lower predisposition to develop drug abuse (Piazza et al., 2000). Similar changes in the dose-response function have been observed after suppression of endogenous GCs in rats (Deroche et al., 1997). Together, these results indicate that GRs are the receptors by which GCs increase the reinforcing effects of cocaine.

\section{Cocaine-induced behavioral and neuronal sensitization in GR $^{\text {NesCre }}$ mice}

\section{Behavioral sensitization}

In control animals, cocaine pretreatment induced a clear-cut behavioral sensitization. This is shown by the higher locomotor response to cocaine observed in animals previously exposed to the drug (chronic cocaine group) compared with animals receiving cocaine for the first time (acute cocaine group) (Fig. 2). In contrast, cocaine-induced behavioral sensitization was completely suppressed in $\mathrm{GR}^{\mathrm{Nes} C r e}$ animals, because the locomotor response in the acute and chronic cocaine groups did not differ. These differences between genotypes were observed both $3 \mathrm{~d}$ (treatment $\times$ genotype interaction, $F_{(2,45)}=5.44 ; p<0.01$ ) and $30 \mathrm{~d}$ after the last injection of the cocaine pretreatment (treatment $\times$ genotype interaction, $\left.F_{(2,43)}=3.35 ; p<0.05\right)$. In contrast to the suppression of sensitization, the acute response to cocaine was preserved in mutant animals, as shown by the higher locomotor response in mutant animals after a single cocaine injection (acute cocaine group) compared with mutant animals that received a vehicle injection (vehicle group) and by the absence of differences between the two genotypes.

\section{Neuronal response to sensitization}

To evaluate cocaine-induced changes in neuronal activity, we quantified c-fos mRNA levels in different brain structures. In all of the brain structures studied, mutant and control animals did not differ in the expression of c-fos mRNA induced by a saline treatment (Fig. 3). In contrast, $\mathrm{GR}^{\mathrm{Nes} C r e}$ mice showed modified
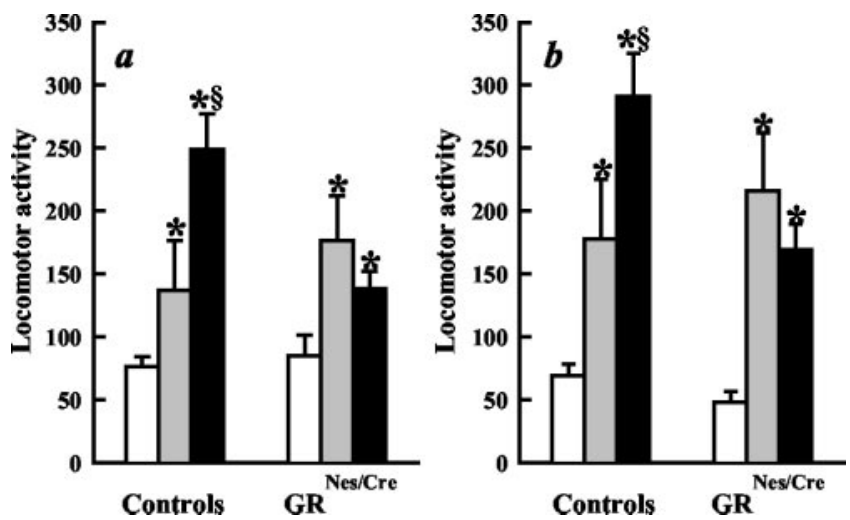

Figure 2. Cocaine-induced behavioral sensitization was suppressed in CNS knock-out of the $\mathrm{GR}\left(\mathrm{GR}^{\text {NesCre }}\right) . a$, Three days after a repeated treatment with either vehicle or cocaine [ 9 injections ( 1 per day) every $2 \mathrm{~d}$ ], cocaine-induced behavioral sensitization was present in control animals. Thus, animals pretreated with cocaine $(\square)$ showed a higher locomotor response to a cocaine challenge $(7.5 \mathrm{mg} / \mathrm{kg})$ than did animals pretreated with saline and receiving either saline $(\square)$ or cocaine (圈). In contrast, sensitization was abolished in GR NesCre animals. However, the acute locomotor response to cocaine ( $\square$ vs 䠗) was preserved in this genotype. $b$, Identical results were found when the challenge for sensitization was performed $30 \mathrm{~d}$ after the last pretreatment injection. Data are expressed as the mean \pm SEM locomotor activity cumulated over 40 min. ${ }^{*} p<0.05$ compared with $\square$; ${ }^{\S} p<0.05$ compared with

responses to cocaine compared with the responses seen in control animals (genotype, $F_{(1,21)}=10.67 ; p<0.01$ ). These differences in c-fos mRNA induction were dependent on the brain structure (genotype $\times$ structure, $F_{(5,105)}=2.87 ; p<0.03$ ) and on the pretreatment (cocaine vs vehicle) (genotype $\times$ drug condition, $\left.F_{(10,105)}=5.20 ; p<0.0001\right)$. In all regions examined, the sensitization of the c-fos response induced by chronic cocaine was suppressed by the absence of GR. In contrast, c-fos gene expression after an acute cocaine injection was decreased only in the nucleus accumbens of mutant animals.

In conclusion, these results show that sensitization to cocaine at both the behavioral and molecular levels is suppressed in the absence of GRs, whereas the acute response to the drug, with the exception of c-fos gene induction in the nucleus accumbens, is not modified by this mutation.

\section{Effect of mifepristone on cocaine SA in rats}

The results obtained in the previous experiments suggest that the GR could be a target for developing new treatments of cocaine addiction. In particular, they suggest that reducing GR activity may decrease the motivation of an individual to self-administer drugs. Vertical downward shifts of SA dose-response functions are indeed considered to reflect a lower motivation to selfadminister cocaine (Piazza et al., 2000). Furthermore, sensitization to the effects of the drug is considered one of the main processes contributing to development of the high motivation for the drug that characterizes drug abusers (Robinson and Berridge, 1993).

Reducing GR activity could be achieved by the use of mifepristone, a potent competitive antagonist of this receptor. We evaluated the potential impact of such a pharmacological manipulation in decreasing the motivation to self-administer cocaine in rats. For this purpose, we used a progressive ratio schedule that is one of the most widely used methods to measure motivation for drugs of abuse (Richardson and Roberts, 1996). It involves progressively increasing the number of responses (ratio) needed to obtain one infusion. Administration of mifepristone reduced the breaking point (last ratio completed) for cocaine SA in a dose- 


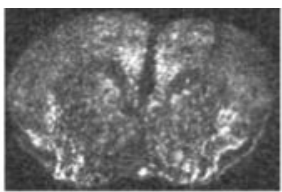

Controls

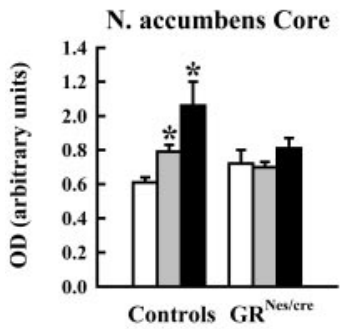

Dorsolateral striatum
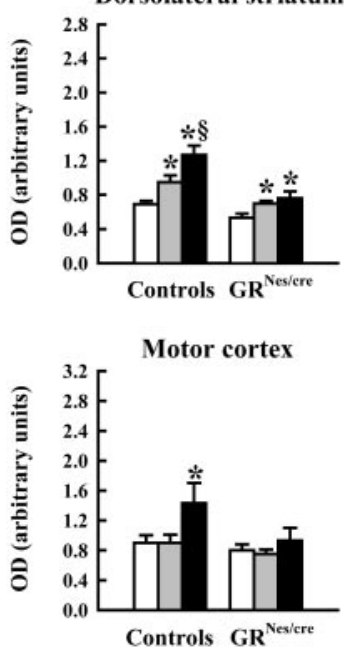

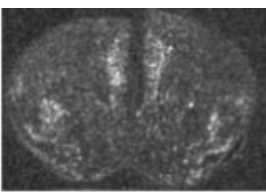

GR $^{\text {NesCre }}$
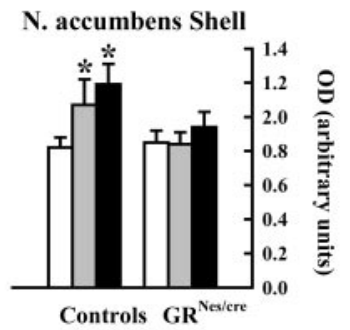

Mediodorsal striatum

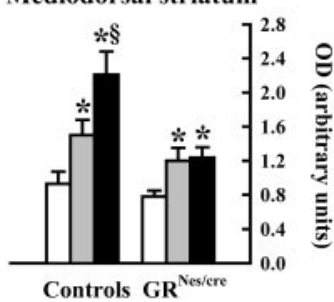

Prefrontal cortex

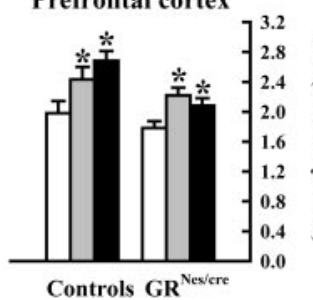

Figure 3. Cocaine-induced neural sensitization was suppressed in CNS knock-out of the GR $\left(G R^{\text {NesCre }}\right)$. GR ${ }^{\text {NesCre }}$ and control mice did not differ in saline-induced $(\square)$ c-fos mRNA expression regardless of the brain structure studied. 0 n the contrary, $G R{ }^{\text {NesCre }}$ mice showed a modified response to cocaine. This effect depended on the brain structure studied and whether the animals were pretreated with cocaine or saline. In all of the brain structures examined here, the sensitization of the c-fos response induced in controls by a pretreatment with cocaine $(\square)$ was suppressed in mutant animals. In contrast, the acute response to cocaine (㗂) was modified by the suppression of the GR only in the nucleus (N.) accumbens. Data are expressed in arbitrary units of $O D$ as the mean \pm SEM. ${ }^{*} p<0.05$ compared with $\square ;{ }^{\S} p<0.05$ compared with 畻. Photographs at the top represent examples of striatal c-fos expression on brain frontal sections (controls on the left, $\mathrm{GR}^{\mathrm{Nes} C r e}$ on the right).

dependent manner (Fig. 4) (treatment effect, $F_{(3,24)}=5.81 ; p<$ $0.004)$. This effect was specific, because the responses measured in the inactive device were not modified. In progressive ratio schedules, large individual differences are classically observed, with some animals showing an extremely high motivation to selfadminister the drug and others showing moderate or low motivation. It has been reported previously that animals with the highest motivation to self-administer cocaine, as characterized by an upward shift of the dose-response function for cocaine SA and a higher performance in a progressive ratio schedule (Piazza et al., 2000), also have a higher functional activity of GCs (Piazza et al., 1991, 1993, 1996). For this reason, we analyzed whether the effects of mifepristone were dependent on the motivation of the animals to self-administer cocaine. For this purpose, we analyzed the results by dividing animals on the basis of their performance in the progressive
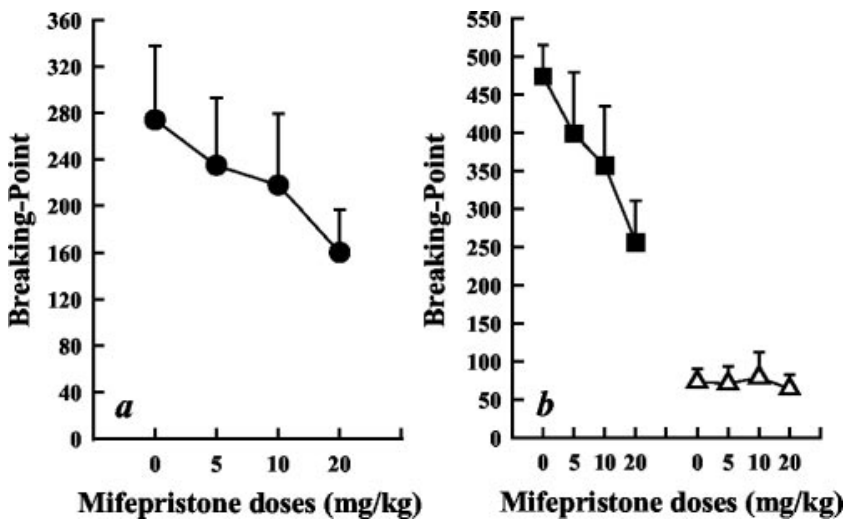

Figure 4. Administration of the GR antagonist mifepristone dose-dependently reduced the breaking point for cocaine SA. a, Mifepristone injection in an entire group of rats ( ) trained in a progressive ratio schedule dose-dependently reduced the breaking point (last ratio completed to obtain 1 infusion). $b$, When animals were divided into two groups on the basis of their performance, we found that the effect of mifepristone was present only in animals with the highest motivation to self-administer cocaine (HPR group, $\square$ ). In contrast, the breaking point of animals with a low motivation to self-administer cocaine (LPR group, $\triangle$ ) was not modified by the GR antagonist. Each point represents the mean \pm SEM breaking point.

ratio schedule. We found that animals with the highest motivation to self-administer cocaine [high progressive ratio (HPR) group] were the only ones in which the breaking point was reduced by mifepristone. In contrast, the breaking point of animals with a low motivation to self-administer cocaine [low progressive ratio (LPR) group] was not modified by the GR antagonist (dose $\times$ group interaction, $F_{(3,24)}=4.81$; $p<0.01)$.

\section{Discussion}

The present experiments provide genetic evidence that brain GRs play an important role in mediating the reinforcing effects of cocaine. Over the last 10 years, pharmacological evidence has accumulated showing that GCs facilitate several behavioral responses to cocaine, including locomotor activity and SA (Piazza et al., 1991; Marinelli et al., 1994, 1997; Goeders and Guerin, 1996; Deroche et al., 1997; Mantsch and Goeders, 1999). Our results demonstrate that cocaine-induced SA involves the GR. In contrast, the locomotor response to an acute cocaine injection does not.

Our study also shows that expression of the GR is a necessary condition for the development of cocaine-induced sensitization at both the behavioral and molecular levels. These findings are important for two reasons. First, sensitization to the effects of the drug is considered to be a major process in the development of drug abuse, because it should mediate the uncontrollable motivation for the drug that characterizes addiction (Robinson and Berridge, 1993). Second, they clarify the involvement of GCs in this neuroadaptive process. Studies analyzing the effect of suppression of endogenous GCs by removal of the adrenal gland or by pharmacological approaches have generated contrasting results (Rivet et al., 1989; Badiani et al., 1995; De Vries et al., 1996; Prasad et al., 1996; Przegalinski et al., 2000). Our experiments, by using a selective genetic invalidation approach, demonstrate that the GR is strongly implicated in the development of sensitization.

The expression of c-Fos is one of the most frequently used markers to monitor neuronal activation and, in particular, the activation induced by psychostimulant drugs. A cocaine-induced increase in c-Fos expression is, at least in part, mediated by an increase in extracellular dopamine (Nestler, 1993; Hyman et al., 
1995) that, by stimulating D1 postsynaptic receptors, activates intracellular signaling pathways. The decrease in c-fos mRNA levels observed here in the nucleus accumbens of mutant animals after acute cocaine could be attributable to changes in extracellular concentrations of dopamine. Thus, it has been shown that suppression of endogenous GCs by adrenalectomy decreases cocaine-induced enhancement of extracellular dopamine in the nucleus accumbens without modifying the sensitivity of D1 receptors to this neurotransmitter. In contrast, the decrease in c-Fos expression observed after sensitization in other brain areas of mutant animals may involve changes in the sensitivity of the D1 receptors. Thus, it has been shown that suppression of endogenous GCs by adrenalectomy has no effect on dopamine release in brain structures such as the dorsal striatum (Barrot et al., 2000, 2001), although it reduces c-Fos expression induced by the direct stimulation of D1 receptors.

Changes in the expression of c-Fos could be involved in mediating some of the effects of the GR on the behavioral responses to cocaine. Thus, the association of fos with jun family members forms the transcription factor activator protein 1 (AP-1), for which cross-talks with the GR have been well established (Herrlich, 2001; Karin and Chang, 2001). Activation of AP-1 has been involved in the molecular changes mediating the long-term adaptive processes leading to addiction (Nestler, 1993, 2001). Consequently, enabling the sensitization of c-Fos and the consequent formation of AP- 1 could be one of the mechanisms by which GCs modify the development of vulnerability to cocaine abuse.

The suppression of sensitization observed in GR mutants could also be responsible for their flattened downward-shifted cocaine self-administration dose-response function and could reflect a lower motivation to self-administer the drug. Thus, it has been shown that repeated exposure to cocaine selfadministration, resulting in sensitization, also induces an upward shift in the cocaine self-administration dose-response function (Schenk and Partridge, 1997) and an increase in motivation for the drug (Mendrek et al., 1998; Deroche et al., 1999; Vanderschuren et al., 1999; Lorrain et al., 2000; Vezina et al., 2002). Furthermore, a downward-shifted self-administration dose-response function similar to the one observed in GR mutants has been demonstrated to reflect a decrease in cocaine efficacy that is associated with lower motivational properties of cocaine (Piazza et al., 2000).

Although the genetic invalidation approach is powerful, the use of knock-outs rather than inducible knock-outs does not allow the influence of a lack of GRs during development to be ruled out. Consequently, it should be considered that the phenotype observed in GR mutants may not reflect directly the potential effects of decreased GR function in the adult. However, several results suggest that for this specific mutation, this is not the case. Thus, we show here that the GR antagonist mifepristone reduces the motivation to self-administer cocaine in an outbred population of rats. Furthermore, suppression of GCs in adult rats induces changes in cocaine self-administration that are identical with the phenotype observed in GR mutant mice (Deroche et al., 1997). Finally, it has been shown previously that administration of mifepristone at the same doses used in our experiment for SA completely reversed amphetamine-induced sensitization (De Vries et al., 1996). This effect is in agreement with the one found here with the suppression of GR expression. Although mifepristone is the most frequently used GR antagonist, it also acts as an antagonist of the progesterone receptors (Baulieu, 1989). However, the results obtained here with the mutant animals allow attribution of the effect of mifepristone on SA and sensitization (De Vries et al., 1996) to the GR.

It is noteworthy that the GR seems to be involved in mediating not the basal behavioral effects of cocaine but, selectively, the excessive response to the drug spontaneously present in certain vulnerable individuals or induced by repeated drug exposure in others. Thus, suppression of the expression of the GR in GR ${ }^{\text {NesCre }}$ animals did not suppress the acquisition of cocaine SA or the basal locomotor response to the drug. In contrast, this mutation completely blocked the enhanced locomotor response to cocaine induced by repeated exposure to cocaine and induced a profound downward shift in the dose-response function for cocaine SA. Similarly, mifepristone did not block the acute response to cocaine but selectively suppressed cocaine-induced sensitization (De Vries et al., 1996) and reduced, as shown here, the breaking point of animals with a peculiar high response to the drug. The effects of genetic suppression of the GR and administration of the GR antagonist on SA are particularly interesting, because they generate a phenotype very similar to the one of animals with a low vulnerability to cocaine (Piazza et al., 2000). These animals, defined as low responders (LRs), in comparison with rats vulnerable to cocaine [high responders (HRs)] (Piazza et al., 1989), show a flat downward-shifted dose-response function for cocaine SA and a very low breaking point (Piazza et al., 2000). These differences between HR and LR animals have been attributed to a higher functional activity of GCs in the HRs (Piazza et al., 1991, 1993, 1996). Our results consequently indicate that the GR is the molecular substrate by which GCs induce a drug-prone state in some vulnerable subjects.

These observations are essential for a potential therapeutic use of GR antagonists. One major problem of drug abuse treatment is indeed that it should reduce excessive drug intake without disrupting the endogenous reward system of the subjects. This is why, for example, dopaminergic antagonists, although they block cocaine effects (Caine and Koob, 1994; Khroyan et al., 2000), are poorly tolerated by drug addicts and therefore of no use for the treatment of addiction (Haney et al., 2001; Nann-Vernotica et al., 2001). The results presented here are, to our knowledge, the first example of pharmacological or genetic manipulations able to modify excessive drug intake without affecting what could be considered the normal reinforcing effects of the drug.

In conclusion, this study shows that GRs are a major molecular substrate of the addictive properties of cocaine, and that GR antagonists could help in the development of new strategies for the treatment of cocaine abuse.

\section{References}

Badiani A, Morano MI, Akil H, Robinson TE (1995) Circulating adrenal hormones are not necessary for the development of sensitization to the psychomotor activating effects of amphetamine. Brain Res 673:13-24.

Barrot M, Marinelli M, Abrous DN, Rouge-Pont F, Le Moal M, Piazza PV (2000) The dopaminergic hyper-responsiveness of the shell of the nucleus accumbens is hormone-dependent. Eur J Neurosci 12:973-979.

Barrot M, Abrous DN, Marinelli M, Rouge-Pont F, Le Moal M, Piazza PV (2001) Influence of glucocorticoids on dopaminergic transmission in the rat dorsolateral striatum. Eur J Neurosci 13:812-818.

Baulieu EE (1989) Contragestion and other clinical applications of RU 486, an antiprogesterone at the receptor. Science 245:1351-1357.

Beato M, Herrlich P, Schutz G (1995) Steroid hormone receptors: many actors in search of a plot. Cell 83:851-857.

Caine SB, Koob GF (1994) Effects of dopamine D-1 and D-2 antagonists on cocaine self-administration under different schedules of reinforcement in the rat. J Pharmacol Exp Ther 270:209-218.

De Kloet ER, Vreugdenhil E, Oitzl MS, Joels M (1998) Brain corticosteroid receptor balance in health and disease. Endocr Rev 19:269-301. 
Deroche V, Marinelli M, Le Moal M, Piazza PV (1997) Glucocorticoids and behavioral effects of psychostimulants. II. Cocaine intravenous selfadministration and reinstatement depend on glucocorticoid levels. J Pharmacol Exp Ther 281:1401-1407.

Deroche V, Le Moal M, Piazza PV (1999) Cocaine self-administration increases the incentive motivational properties of the drug in rats. Eur J Neurosci 11:2731-2736.

De Vries TJ, Schoffelmeer AN, Tjon GH, Nestby P, Mulder AH, Vanderschuren LJ (1996) Mifepristone prevents the expression of long-term behavioural sensitization to amphetamine. Eur J Pharmacol 307:R3-R4.

Franklin KBJ, Paxinos G (1997) The mouse brain in stereotaxic coordinates. San Diego: Academic.

Gagne D, Pons M, Philibert D (1985) RU 38486: a potent antiglucocorticoid in vitro and in vivo. J Steroid Biochem 23:247-251.

Goeders NE (2002) The HPA axis and cocaine reinforcement. Psychoneuroendocrinology 27:13-33.

Goeders NE, Guerin GF (1996) Effects of surgical and pharmacological adrenalectomy on the initiation and maintenance of intravenous cocaine self-administration in rats. Brain Res 722:145-152.

Hafezi-Moghadam A, Simoncini T, Yang E, Limbourg FP, Plumier JC, Rebsamen MC, Hsieh CM, Chui DS, Thomas KL, Prorock AJ, Laubach VE, Moskowitz MA, French BA, Ley K, Liao JK (2002) Acute cardiovascular protective effects of corticosteroids are mediated by non-transcriptional activation of endothelial nitric oxide synthase. Nat Med 8:473-479.

Haney M, Ward AS, Foltin RW, Fischman MW (2001) Effects of ecopipam, a selective dopamine D1 antagonist, on smoked cocaine selfadministration by humans. Psychopharmacology (Berl) 155:330-337.

Herrlich P (2001) Cross-talk between glucocorticoid receptor and AP-1. Oncogene 20:2465-2475.

Hyman SE, Cole RL, Konradi C, Kosofsky BE (1995) Dopamine regulation of transcription factor-target interactions in rat striatum. Chem Senses 20:257-260

Jaber M, Dumartin B, Sagne C, Haycock JW, Roubert C, Giros B, Bloch B, Caron MG (1999) Differential regulation of tyrosine hydroxylase in the basal ganglia of mice lacking the dopamine transporter. Eur J Neurosci 11:3499-3511.

Karin M, Chang L (2001) AP-1-glucocorticoid receptor crosstalk taken to a higher level. J Endocrinol 169:447-451.

Khroyan TV, Barrett-Larimore RL, Rowlett JK, Spealman RD (2000) Dopamine D1- and D2-like receptor mechanisms in relapse to cocaine-seeking behavior: effects of selective antagonists and agonists. J Pharmacol Exp Ther 294:680-687.

Koob GF, Weiss F (1990) Pharmacology of drug self-administration. Alcohol 7:193-197.

Lorrain DS, Arnold GM, Vezina P (2000) Previous exposure to amphetamine increases incentive to obtain the drug: long-lasting effects revealed by the progressive ratio schedule. Behav Brain Res 107:9-19.

Makara GB, Haller J (2001) Non-genomic effects of glucocorticoids in the neural system: evidence, mechanisms and implications. Prog Neurobiol 65:367-390.

Mantsch JR, Goeders NE (1999) Ketoconazole blocks the stress-induced reinstatement of cocaine-seeking behavior in rats: relationship to the discriminative stimulus effects of cocaine. Psychopharmacology 142:399-407.

Marinelli M, Piazza PV, Deroche V, Maccari S, Le Moal M, Simon H (1994) Corticosterone circadian secretion differentially facilitates dopaminemediated psychomotor effect of cocaine and morphine. J Neurosci 14:2724-2731.

Marinelli M, Rouge-Pont F, Deroche V, Barrot M, De Jesus-Oliveira C, Le Moal M, Piazza PV (1997) Glucocorticoids and behavioral effects of psychostimulants. I. Locomotor response to cocaine depends on basal levels of glucocorticoids. J Pharmacol Exp Ther 281:1392-1400.

McEwen BS, De Kloet ER, Rostene W (1986) Adrenal steroid receptors and actions in the nervous system. Physiol Rev 66:1121-1188.

Mendrek A, Blaha CD, Phillips AG (1998) Pre-exposure of rats to amphet- amine sensitizes self-administration of this drug under a progressive ratio schedule. Psychopharmacology 135:416-422.

Nann-Vernotica E, Donny EC, Bigelow GE, Walsh SL (2001) Repeated administration of the D1/5 antagonist ecopipam fails to attenuate the subjective effects of cocaine. Psychopharmacology 155:338-347.

Nestler EJ (1993) Cellular responses to chronic treatment with drugs of abuse. Crit Rev Neurobiol 7:23-39.

Nestler EJ (2001) Molecular basis of long-term plasticity underlying addiction. Nat Rev Neurosci 2:119-128.

Piazza PV, Le Moal M (1997) Glucocorticoids as a biological substrate of reward: physiological and pathophysiological implications. Brain Res Brain Res Rev 25:359-372.

Piazza PV, Le Moal M (1998) The role of stress in drug self-administration. Trends Pharmacol Sci 19:67-74.

Piazza PV, Deminiere J-M, Le Moal M, Simon H (1989) Factors that predict individual vulnerability to amphetamine self-administration. Science 245:1511-1513.

Piazza PV, Maccari S, Deminiere JM, Le Moal M, Mormede P, Simon H (1991) Corticosterone levels determine individual vulnerability to amphetamine self-administration. Proc Natl Acad Sci USA 88:2088-2092.

Piazza PV, Deroche V, Deminiere JM, Maccari S, Le Moal M, Simon H (1993) Corticosterone in the range of stress-induced levels possesses reinforcing properties: implications for sensation-seeking behaviors. Proc Natl Acad Sci USA 90:11738-11742.

Piazza PV, Rouge-Pont F, Deroche V, Maccari S, Simon H, Le Moal M (1996) Glucocorticoids have state-dependent stimulant effects on the mesencephalic dopaminergic transmission. Proc Natl Acad Sci USA 93:8716-8720.

Piazza PV, Deroche-Gamonet V, Rouge-Pont F, Le Moal M (2000) Vertical shifts in self-administration dose-response functions predict a drugvulnerable phenotype predisposed to addiction. J Neurosci 20:4226-4232.

Prasad BM, Ulibarri C, Kalivas PW, Sorg BA (1996) Effect of adrenalectomy on the initiation and expression of cocaine-induced sensitization. Psychopharmacology 125:265-273.

Przegalinski E, Filip M, Siwanowicz J, Nowak E (2000) Effect of adrenalectomy and corticosterone on cocaine-induced sensitization in rats. J Physiol Pharmacol 51:193-204.

Richardson NR, Roberts DC (1996) Progressive ratio schedules in drug selfadministration studies in rats: a method to evaluate reinforcing efficacy. J Neurosci Methods 66:1-11.

Rivet JM, Stinus L, Le Moal M, Mormede P (1989) Behavioral sensitization to amphetamine is dependent on corticosteroid receptor activation. Brain Res 498:149-153.

Robinson TE, Berridge KC (1993) The neural basis of drug craving: an incentive-sensitization theory of addiction. Brain Res Brain Res Rev 18:247-291.

Sapolsky RM, Romero LM, Munck AU (2000) How do glucocorticoids influence stress responses? Integrating permissive, suppressive, stimulatory, and preparative actions. Endocr Rev 21:55-89.

Schenk S, Partridge B (1997) Sensitization and tolerance in psychostimulant self-administration. Pharmacol Biochem Behav 57:543-550.

Schuster CR, Thompson T (1969) Self administration of and behavioral dependence on drugs. Annu Rev Pharmacol 9:483-502.

Tronche F, Kellendonk C, Kretz O, Gass P, Anlag K, Orban PC, Bock R, Klein R, Schütz G (1999) Disruption of the glucocorticoid receptor gene in the nervous system results in reduced anxiety. Nat Genet 23:99-103.

Vanderschuren LJ, Schoffelmeer AN, Mulder AH, De Vries TJ (1999) Dopaminergic mechanisms mediating the long-term expression of locomotor sensitization following pre-exposure to morphine or amphetamine. Psychopharmacology 143:244-253.

Vezina P, Lorrain DS, Arnold GM, Austin JD, Suto N (2002) Sensitization of midbrain dopamine neuron reactivity promotes the pursuit of amphetamine. J Neurosci 22:4654-4662. 